\title{
HOMOCYSTEINE STATUS OF ELDERLY SLUM WOMEN IN DELHI
}

\section{ZAOZIANLUNGLIU GONMEI ${ }^{1}$, SUPRIYA DWIVEDI ${ }^{1}$, ANUPA SIDDHU ${ }^{2}$, GURUDAYAL SINGH TOTEJA ${ }^{1,3 *}$, NAVAL KISHORE VIKRAM ${ }^{4}$, PREETI KAMBOJ ${ }^{1}$}

${ }^{1}$ Centre for Promotion of Nutrition Research and Training with special focus on North East, Tribal and Inaccessible Population (Indian Council of Medical Research), New Delhi, India. ${ }^{2}$ Department of Food and Nutrition, Lady Irwin College, University of Delhi, New Delhi, India. ${ }^{3}$ Desert Medicine Research Centre (Indian Council of Medical Research), Jodhpur, Rajasthan, India. ${ }^{4}$ Department of Medicine, All India Institute of Medical Sciences, New Delhi, India. Email: gstoteja@gmail.com

Received: 29 January 2018, Revised and Accepted: 01 May 2018

ABSTRACT

Objective: The study was undertaken to assess homocysteine levels among economically deprived elderly women in Delhi.

Methods: The study was carried out among elderly women aged 60-70 years residing in Kirti Nagar slums of West Delhi. Blood samples were collected, and serum homocysteine was analyzed using chemiluminescent immunometric assay. Hyperhomocysteinemia was defined as serum homocysteine $>15 \mu \mathrm{mol} / \mathrm{l}$. Dietary information was also collected using $24 \mathrm{~h}$ dietary recall method and food frequency questionnaire.

Results: The prevalence of hyperhomocysteinemia was $16.9 \%$. The mean serum homocysteine was $12.35 \pm 6.43 \mu$ mol/l. Serum homocysteine levels ranged from 3.84 to $35.20 \mu \mathrm{mol} / \mathrm{l}$. It was observed that hyperhomocysteinemia was higher in vegetarians (31.2\%) compared to non-vegetarians $(6.7 \%)$.

Conclusion: The prevalence of hyperhomocysteinemia is higher among vegetarians than non-vegetarians. Further, research is necessary to see the effect of elevated homocysteine in multiple age-related diseases.

Keywords: Elderly women, Homocysteine, Hyperhomocysteinemia.

(C) 2018 The Authors. Published by Innovare Academic Sciences Pvt Ltd. This is an open access article under the CC BY license (http://creativecommons. org/licenses/by/4. 0/) DOI: http://dx.doi.org/10.22159/ajpcr.2018.v11i7.25003

\section{INTRODUCTION}

The prevalence of hyperhomocysteinemia is higher in elderly and is responsible for an increased risk of age-related diseases, namely vascular diseases, cognitive decline, dementia, depression, osteoporotic fracture, and functional decline [1-3]. Meta-analysis of 83 studies involving 35,758 individuals indicated elevated level of homocysteine and folate deficiency which is associated with increased risk of cancer [4]. Homocysteine level of $\geq 10.8 \mu \mathrm{mol} / \mathrm{l}$ is likely to be responsible for all-cause mortality and cardiovascular events [5]. Another meta-analysis of 72 studies revealed that lowering homocysteine concentrations can reduce risk of ischemic heart disease and stroke [6]. A study undertaken among adults aged 30-75 years with and without metabolic syndrome revealed that patients with metabolic syndrome had increased homocysteine level [7]. Studies carried out in India indicated a significant correlation between hyperhomocysteinemia and coronary artery disease $[8,9]$.

The prevalence of hyperhomocysteinemia depends on the type of population, age group, dietary pattern, and genetic background $[10,11]$. Studies carried out in India reported the prevalence of hyperhomocysteinemia ranging from $13 \%$ to $84 \%$. However, there are limited data available on homocysteine level of elderly in India. The present study was undertaken to assess homocysteine status of economically deprived elderly women in Delhi.

\section{METHODS}

The study was carried out in Kirti Nagar slums of West Delhi, India. Fifty nine elderly women aged $60-70$ years were enrolled in the study. Institutional ethical clearance was obtained, and informed consent was taken from all the study participants. Blood samples were collected and analyzed for serum homocysteine. Dietary intake of nutrients was also collected using $24 \mathrm{~h}$ recall method and food frequency questionnaire.

Five ml venous blood was collected in Becton Dickinson vacutainers and was then centrifuged for $10 \mathrm{~min}$ at $1500 \mathrm{rpm}$ to separate serum. Separated serum samples were transported to the laboratory in cold chain and were stored at $-80^{\circ} \mathrm{C}$ till analysis. Homocysteine was analyzed using chemiluminescent immunometric assay (Immulite 1000 analyzer, Siemens). Samples were analyzed at a National Accreditation Board for Testing and Calibration Laboratories (NABL) Accredited Laboratory, Centre for Promotion of Nutrition Research and Training with special focus on North-East, Tribal and Inaccessible Population (Indian Council of Medical Research), New Delhi. Hyperhomocysteinimia was defined as serum homocysteine $>15 \mu \mathrm{mol} / \mathrm{l}[12]$

\section{RESULTS}

A total of 59 elderly women were enrolled in the study. Of 59 elderly enrolled, 10 (16.9\%) had hyperhomocysteinemia. The mean serum homocysteine was $12.35 \pm 6.43 \mu \mathrm{mol} / \mathrm{l}$. Serum homocysteine levels ranged from 3.84 to $35.20 \mu \mathrm{mol} / \mathrm{l}$. Dietary information was collected from 46 elderly. Among them, $65 \%$ were non-vegetarian $(n=30)$ and remaining were vegetarian $(n=16)$. Five of 16 vegetarians $(31.2 \%)$ and two of 30 non-vegetarians $(6.7 \%)$ had hyperhomocysteinemia (Table 1).

\section{DISCUSSION}

Our study indicated the prevalence of hyperhomocysteinemia among elderly women as $16.9 \%$. A study carried out in Bengaluru, Karnataka, India, among 175 elderly revealed the prevalence of hyperhomocysteinemia as $13 \% 10$. Another study carried out among 137 women from Mumbai, Maharashtra, India, aged 36-71 years 
Table 1: Homocysteine levels of elderly women according to food habits

\begin{tabular}{|c|c|c|c|}
\hline Food habits & $\mathbf{n}$ & Serum homocysteine $>15 \mu \mathrm{mol} / \mathrm{l}$ n (\%) & Serum homocysteine $\leq 15 \mu \mathrm{mol} / \mathrm{l}$ n (\%) \\
\hline Vegetarian & 16 & $5(31.2)$ & $11(68.8)$ \\
\hline Non-vegetarian & 30 & $2(6.7)$ & $28(93.3)$ \\
\hline
\end{tabular}

$n=46$

indicated slightly higher prevalence of hyperhomocysteinemia that is $24.2 \%[13]$.

Higher prevalence (50-80\%) of hyperhomocysteinemia has also been reported among adults in India. A study carried out among middleaged men in Pune, Maharashtra, India, reported the prevalence of hyperhomocysteinemia as 58\% [14]. Similarly, a study carried out among 448 middle-aged men living in an urban slum in the southern area of New Delhi, India, reported hyperhomocysteinemia among $84 \%$ of the study population [15]. Hyperhomocysteinemia was also reported among $55 \%$ of study volunteers in a study carried out among 970 volunteers aged 35-86 years in Dispur, Assam, India [16]. Elevated homocysteine levels are also reported in China, Taiwan, Iran, and Pakistan. A meta-analysis covering 60,754 subjects derived from 36 studies carried out in China estimated overall prevalence of hyperhomocysteinemia as $27.5 \%$ [17]. A study carried out in Taiwan covering 1094 males and 1135 females aged 65-90 years reported the prevalence of hyperhomocysteinemia, respectively, as $23.4 \%$ and $11.2 \%$ among elderly males and females [18]. The homocysteine survey carried out among 1214 people aged 25-64 years in Tehran reported hypermocysteinemia among $73.1 \%$ and $41.07 \%$ in men and women, respectively [19].

Elevated homocysteine level can be either due to deficiency of folate or Vitamin $B_{12}$ [20]. A recent study carried out in China among 330 study volunteers also reported folate and Vitamin $B_{12}$ deficiency as well as MTHFR C677T polymorphism were significantly associated with elevated serum homocysteine levels [21]. Higher prevalence of hyperhomocysteinemia has been reported among vegetarians mainly due to Vitamin $B_{12}$ deficiency [22]. A systematic review and meta-analysis of studies involving 3230 volunteers revealed that homocysteine levels are elevated at low serum Vitamin $B_{12}$ levels [23]. Our study also indicated higher prevalence of hyperhomocysteinemia among vegetarians (31.2\%) than non-vegetarians (6.7\%). A crosssectional study carried out among 200 volunteers in Lucknow also revealed that the prevalence of hyperhomocysteinemia was lower in non- vegetarians than vegetarians [24]. A study carried out in Pakistan among 200 healthy volunteers also reported that vegetarians (30\%) as compared to non-vegetarians $(6 \%)$ are more prone to develop hyperhomocysteinemia [25]. Studies carried out in Taiwan, Italy, and Turkey, also reported higher homocysteine level among vegetarians compared to non-vegetarians [26-28].

\section{CONCLUSION}

The prevalence of hyperhomocysteinemia is higher among vegetarians than non-vegetarians. Further, research is necessary to see the effect of elevated homocysteine in multiple age-related diseases.

\section{CONFLICTS OF INTEREST}

The authors declare that there are no conflicts of interest.

\section{AUTHOR'S CONTRIBUTIONS}

Equal contribution, Zaozianlungliu Gonmei: Data collection and paper writing, Supriya Dwivedi: Data analysis and paper writing, Dr. Anupa Siddhu: Conceptualization of study and interpretation of data, Dr. Gurudayal Singh Toteja: Conceptualization of study, interpretation of data, and paper writing, Dr. Naval Kishore Vikram: Interpretation of data, Preeti Kamboj: Paper writing.

\section{REFERENCES}

1. Mattson MP, Duan WK. Folic acid and homocysteine in age-related disease. Ageing Res Rev 2002;1:95-111.

2. Kuo HK, Sorond FA, Chen JH, Hashmi A, Milberg WP, Lipsitz LA. The role of homocysteine in multisystem age-related problems: A systematic review. J Gerontol A Biol Sci Med Sci 2005;60:1190-2001.

3. Aklil B, Zerizer S, Kabouche Z. The protective effects of Argania spinosa seeds against hyperhomocystenemia induced by high methionine diet in mice. Int J Pharm Pharm Sci 2017;9:64-9.

4. Zhang D, Wen X, Wu W, Guo Y, Cui W. Elevated homocysteine level and folate deficiency associated with increased overall risk of carcinogenesis: Meta-analysis of 83 case-control studies involving 35,758 individuals. PLoS One 2015;10:e0123423.

5. Petersen JF, Larsen BS, Sabbah M, Nielsen OW, Kumarathurai P, Sajadieh A. Longterm prognostic significance of homocysteine in middle-aged and elderly. J Biomarkers 2016;21:490-6.

6. Wald DS, Law M, Morris JK. Homocysteine and cardiovascular disease: Evidence on causality from a meta-analysis. BMJ 2002;325:1202.

7. Sreckovic B, Sreckovic VD, Soldatovic I, Colak E, SumaracDumanovic M, Janeski $\mathrm{H}$, et al. Homocysteine is a marker for metabolic syndrome and atherosclerosis. Diabetes Metab Syndr 2017; 11:179-82.

8. Gupta SK, Kotwal J, Kotwal A, Dhall A, Garg S. Role of homocysteine and MTHFR C677T gene polymorphism as risk factors for coronary artery disease in young Indians. Indian J Med Res 2012;135:506-12.

9. Sahu A, Gupta T, Kavishwar A, Singh RK. Cardiovascular diseases risk prediction by homocysteine in comparison to other markers: A study from Madhya Pradesh. J Assoc Phys India 2015;63:37-40.

10. Faeh D, Chiolero A, Paccaud F. Homocysteine as a risk factor for cardiovascular disease: should we (still) worry about it? Swiss Med Wkly 2006;136:745-56.

11. Souad L, Cherifa A, Naimi D. The effects of homocysteine on plasma biochemical parameters and aortic matrix metalloproteinases activities. Int J Pharm Pharm Sci 2015;7:459-62.

12. Shobha V, Tarey SD, Singh RG, Shetty P, Unni US, Srinivasan S, et al. Vitamin B12 deficiency \& levels of metabolites in an apparently normal urban south Indian elderly population. Indian J Med Res 2011;34:32-9.

13. Pandey SN, VaidyaAD, Vaidya RA, Talwalkar S. Hyperhomocysteinemia as a cardiovascular risk factor in Indian women: Determinants and directionality. JAPI 2006;54:769-74.

14. Yagnik CS, Deshpande SS, Lubree HG, Naik SS, Bhat DS, Uradev BS, et al. Vitamin B12 deficiency and hyperhomocystenemia in rural and urban Indians. J Assoc Phys India 2006;54:775-82.

15. Misra A, Vikram NK, Pandey RM, Dwivedi M, Ahmad FU, Luthra K, et al. Hyperhomocysteinemia, and low intakes of folic acid and vitamin B12 in urban North India. Eur J Nutr 2002;41:68-77.

16. Das M, Ghose M, Borah NC, Choudhury N. A community based study of the relationship between homocysteine and some of the life style factors. Indian J Clin Biochem 2010;25:295-301.

17. Yang B, Fan S, Zhi X, Wang Y, Wang Y, Zheng Q, et al. Prevalence of hyperhomocysteinemia in China: A systematic review and metaanalysis. Nutrients 2015;7:74-90.

18. Chen KJ, Pan WH, Yang FL, Wei IL, Shaw NS, Lin BF. Association of $\mathrm{B}$ vitamins status and homocysteine levels in elderly Taiwanese. Asia Pac J Clin Nutr 2005;14:250-5.

19. Fakhrzadeh H, Ghotbi S, Pourebrahim R, Nouri M, Heshmat R, Bandarian F, et al. Total plasma homocysteine, folate, and vitamin b12 status in healthy Iranian adults: The Tehran homocysteine survey (2003-2004)/a cross - sectional population based study. BMC Public Health 2006;6:29.

20. Clarke R, Refsum H, Birks J, Evans JG, Johnston C, Sherliker P, et al. Screening for vitamin B-12 and folate deficiency in older persons. Am J Clin Nutr 2003;77:1241-7.

21. Ni J, Zhang L, Zhou T, Xu WJ, Xue JL, Cao N, et al. Association between the MTHFR C677T polymorphism, blood folate and vitamin B12 deficiency, and elevated serum total homocysteine in healthy individuals in Yunnan Province, China. J Chin Med Assoc 
2017;80:147-53.

22. Pawlak R. Vitamin B12 in vegetarian diets. Middle East J Rehabil Health 2015;2:e32907.

23. Obersby D, Chappell DC, Dunnett A, Tsiami AA. Plasma total homocysteine status of vegetarians compared with omnivores: A systematic review and meta-analysis. Br J Nutr 2013;109:785-94.

24. Kalita J, Misra UK, Srivastava AK, Bindu IS. A study of homocysteine level in North Indian subjects with special reference to their dietary habit. e-SPEN 2007;2:e116-9.

25. Kapoor A, Zuberi NA, Rathore MI, Baig M. Serum homocysteine level in vegetarians in District Tharparker, Sindh. Pak J Med Sci
2015;31:127-30

26. Chen $\mathrm{CW}$, Lin YL, Lin TK, Lin CT, Chen BC, Lin CL. Total cardiovascular risk profile of Taiwanese vegetarians. Eur J Clin Nutr 2008;62:138-44.

27. Bissoli L, Di Francesco V, Ballarin A, Mandragona R, Trespidi R, Brocco G, et al. Effect of vegetarian diet on homocysteine levels. Ann Nutr Metab 2002;46:73-9.

28. Karabudak E, Kiziltan G, Cigerim N. A comparison of some of the cardiovascular risk factors in vegetarian and omnivorous Turkish females. J Hum Nutr Diet 2008;21:13-22. 